International Journal of Linguistics, Literature and Translation

ISSN: 2617-0299 (Online); ISSN: 2708-0099 (Print)

DOI: $10.32996 / \mathrm{ijllt}$

Journal Homepage: www.al-kindipublisher.com/index.php/ijllt

\title{
Investigating Gender Differences in Iranian EFL Learners' Rounded Vowels
}

\author{
Mohammad Mehdi Tahanzadeh ${ }^{1}$ 8(D), Mansoore Shekaramiz ${ }^{2}$ (D) $\triangle$, Marjan Abyavi $^{3}$ \& $(D)$ and Reihaneh \\ Shamei $^{4}$ Q (D) \\ ${ }^{1}$ MA in TEFL, Department of English, Faculty of Humanities, Ahvaz Branch, Islamic Azad University, Ahvaz, Iran \\ ${ }^{2}$ Assistant Professor, Department of English, Faculty of Humanities, Ahvaz Branch, Islamic Azad University, Ahvaz, Iran \\ ${ }^{3}$ Department of English, Faculty of Humanities, Ahvaz Branch, Islamic Azad University, Ahvaz, Iran \\ ${ }^{4}$ Department of Linguistics, Ahvaz Branch, Islamic Azad University, Ahvaz, Iran
}

$\square$ Corresponding Author: Mansoore Shekaramiz, E-mail: mansoore.shekaramiz@gmail.com

\section{ARTICLE INFORMATION ABSTRACT}

Received: March 11, 2021

Accepted: April 21, 2021

Volume: 4

Issue: 4

DOI: $10.32996 /$ ijllt.2021.4.4.23

\section{KEYWORDS}

Gender differences, English round vowels, Iranian EFL learners' speech, first formant (F1), second formant (F2), acoustic phonetics, rounded vowels
The present study investigated the gender differences in producing all English rounded vowels /u:/, / :/, / / and /o/ in Iranian EFL learners' speech in comparison with native ones. Sixty Iranian EFL learners including 30 males and 30 females were selected as the participants of this study. Oxford proficiency test (OPT, 2001) was conducted in order to ensure the learners were truly homogenous with regard to their English proficiency level. All learners were right-handed, Persian monolingual native speakers with no brain injuries, hearing or visual problems that interfered with their performance in the test. Four words containing English round vowels with CVC syllable structure were selected and put inside the carrier sentence "Say......please". In fact, each learner uttered the carrier sentences separately. Via PRAAT software (win 64), the voices of the participants were recorded and analyzed for obtaining the first and the second formants (F1 and F2) of each vowel. The obtained data from male and female speeches were compared to each other to find their differences. The results showed in F2 values, there were gender differences considering the consonantal context. This study demonstrated that for males, the degree of backness of vowel /u:/ was less than that of vowel / $/$ /, but for females it was vice versa. For both vowels, male's mean F1 was lower than female's mean F1 and male's mean F2 was higher than female's mean F2. The present study showed gender differences in producing English rounded vowels. So, the results can be used in classes which contain only one gender. The findings of this study can bring about some pedagogical implications for teaching English diphthongs, triphthongs and English rounded vowels.

\section{Introduction}

"Phonetics is a branch of linguistics which is concerned with the production, physical nature, and perception of speech sounds. The main fields of study are experimental phonetics, articulatory phonetics, phonemics, acoustic phonetics, and auditory phonetics" (Birjandi \& Salmani-Nodoushan, 2005, p. 1). In fact, acoustic phonetics is called one of the sub-branches of phonetics which according to Birjandi and Salmani-Nodoushan (2005) is "the study of the sound waves produced by the human vocal apparatus"(p. 6), therefore, this study can be called physical properties of speech sounds. They also mention that this area of phonetics relates to the study of three topics: (a) the acoustical properties of speech sounds, (b) voice quality and (c) prosody. "It forms not only the immediate link between speech production (i.e., articulatory phonetics) and speech perception (i.e., auditory phonetics), but is also important for applications in the fields of signal processing and speech technology"(Birjandi \& SalmaniNodoushan, 2005, p. 149).

\section{K C AL-KINDI CENTER R D FOR RESEARCH AND DEVELOPMENT} Your gateway to world-class research

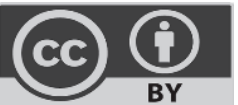

Published by Al-Kindi Center for Research and Development, London, United Kingdom. Copyright (c) the author(s). This open access article is distributed under a Creative Commons Attribution (CC-BY) 4.0 license 
In acoustic phonetics, acoustic analysis can be conducted via PRAAT software which provides the facility not only to record but also to analyze sound waves. PRAAT shows their spectrograms additionally. Not long after the introduction of the sound spectrograph, Peterson and Barney (1952) carried out a simple study on the acoustics and perception of vowels at Bell Telephone Laboratories. Now that study is considered the most cited experiment according to Hillenbran, Getty, Clark, and Wheeler (1995) who mentioned that "Peterson and Barney (PB) measurements have played a central role in the development and testing of theories of vowel recognition" (p. 3099), besides they reported that the acoustic measurements of PB study have been distributed and used in other speech researches.

Therefore, from years ago researchers were interested in both the study of acoustic phonetics and analyzing human speech indeed (e.g. Nittrouer, Mcgowan, Milenkovic, \& Beehler, 1990; Busby \& Plant,1995; Namaziandost \& Shafiee, 2018) and by doing so, they could find some differences between male and female speech, since they were biologically different and it was due to the differences between their larynx and the hormones which affected the brain. On the contrary, biological factors are not the only reasons that can cause these differences; society also may cause some differences, so they also have sociolinguistic differences. These factors affect different aspects of their lives, one of these aspects is the way they speak and produce the sounds of language.

For instance, as Holmes says "women are more linguistically polite than men"(1992, p. 157). He also mentioned that women use "more standard forms than men and men use more vernacular forms than women"(p. 160). According to Labov,"women conform more closely than men to sociolinguistic norms that are overtly prescribed, but conform less than men when they are not"(2001, p. 281). As a matter of fact, one of the significant differences between male and female speech refers back to the way they produce vowels.

For example, Ladefoged and Farrari Disner say: "the men's vowels have lower formant frequencies", then they mentioned the reason; "this is because men have larger vocal tracts containing bigger bodies of air, these larger bodies of air vibrate more slowly, so that the formants have lower frequencies" (2012, p. 44). When male and female have different mother language, this difference can be transferred to the learning of a foreign language. For instance, in Persian it has been reported that males and females are different in producing Persian round vowels $/ \mathrm{u} / \mathrm{and} / \mathrm{J} /$; females produce them very similar to each other. Nevertheless, males produce them differently (Shekaramiz, 2014; Namaziandost, Abedi, \& Nasri, 2019), and this difference can be transferred to the producing of English round vowels. Finally, purpose of this study is to study investigate gender differences in producing all English rounded vowels which comprise /u:/, / :/, / / and /O/among Iranian EFL learners' speech in comparison with native ones.

\section{Literature Review}

\subsection{Theoretical Background}

It is really amazing when a child is born, everyone tends to wait for the first vocal performance which can be called the cry of life. Thus, human voice can play significant role from the beginning and additionally its importance remains throughout life.

As a matter of fact, sounds are considered to be air waves which can be received and heard by ears. "Waves of compression move steadily outward. Consequently, a listening ear will experience moments of higher pressure followed by moments of lower pressure, so that the sensation of sound results" (Ladefoged, 1996, p. 8). Actually, when something makes appropriate variation in air pressure it can be called a source of sound, therefore human voice is a source of sound by virtue of the fact that human can make this kind of variation by using vocal organs, such as lips, tongue, and vocal cords (Ladefoged, 1996; Namaziandost, Sabzevari, \& Hashemifardnia, 2018). Thus, the speech can be produced by human.

Not only is speech primary but also is universal expression of language (Fry, 2009). During speech production, the air waves are constricted at the vocal folds (Stevens, 2000). According to Fry (2009), it can be investigated from three points of view; (1) Psychology: a field which linguistic activities in speech such as memorization of words, grammatical forms, and organization of words in sentences can be studied. (2) Physiology: in which I can study how either muscles or nerves operate during the process of articulating of speech sounds. (3) Physics: through which I can both survey and study the way of how sound waves are generated, transmitted, and also received. Hence, I am able to work on the language system through studying on muscles, memory, nerves and sound waves indeed.

The sound waves of speech are vital parts, in fact in the communication process (Fry, 2009). "The measurement of sound waves and the examination of the links between the features of speech sound waves and the working of linguistic systems is the task of one specific part of experimental phonetics, acoustic phonetics" (Fry, 2009, p. 11).

According to (Jongman, 2013), acoustic phonetics can be considered to be the study of the acoustic characteristics of speech that includes analyzing and describing its physical properties (duration, frequency, and intensity). Signal can be stored, 
replicated, visualized, and analyzed through acoustic phonetics the speech; thus, it is considered to be an instrumental science. In acoustic phonetics, older research continues to be influential, thus it is also a cumulative science (Jongman, 2013).

For language teachers, learning acoustic phonetics can play a significant role, because it can make them able to apply in their teaching of pronunciation procedure. In case of acoustic phonetics, acoustic analysis is called to be a basic tool that the distribution of speech sound energy is shown by acoustic spectrum in terms of both frequency and intensity (Fry, 2009). In studying speech, the transient property of sounds is one of the main problems, In addition, they can be recalled by utilizing some forms of recording or by repeating the words, although it is a copy and not the original sound itself (Ladefoged, 1996), nevertheless it can be helpful and essential in some studies like analyzing speech sounds. The researcher can find some applications for acoustic analysis. One of the best one is PRAAT in which determines some properties of speech sounds, and illustrates some detailed information about physical properties of speech sounds such as, sound intensity, frequency and passage of time indeed. This kind of information would be collected and applied for different field of investigation into similar cases and studies such as, studies on the differences between male and female speech. Thus, it is a considered to be utilizable and necessary tool in case of acoustic analysis studies.

According to Pepiot (2015), gender difference is a complex issue, it can refer to some fields such as, acoustic, perceptual measurements, anatomy, physiology, sociology and finally philosophy. Thus, gender differences can play an important role in various areas for example, the construction of gender identity, fundamental frequency, resonant frequencies, innate versus learned behavior and finally the differences in the vocal organs indeed. Pepiot (2015) believes that the difference in mean fundamental frequency, which has been related to pitch, is considered to be the major one among other differences of adult male and female voices. He continues which mean F0 for female would be around $200 \mathrm{~Hz}$ and for male is $120 \mathrm{~Hz}$. These values also can be various in different ages for the same gender. So, both male and female can be different in different aspects including the way which they tend to produce speech sounds. For example, in the case of producing vowels which they are different in.

As mentioned before, vowels are produced when the air passes freely through the oral cavity. According to Birjandi and SalmaniNodoushan, vowels are divided into some categories: (1) Based on the shape of the mouth, actually either they can be rounded (/u:/) or unrounded (/e/). In fact, during the procedure of producing rounded vowels lips are pushed forward. (2) They can be long Based on the time or duration of articulation (/i:/) and short like (/I/). More time would be used in producing long vowels than in producing short vowels, it proves that they have more duration of articulation. (3) Based on the position of the tongue in the mouth, therefore they can be front (/æ/), central (/ə/), and also be back (/כ:/) vowels. The tongue would be in the pre-palatal part of the mouth in front vowels, the tongue position would be in the medio- palatal part in central vowels, and in fact, in back vowels the tongue is in the post- palatal part of the mouth. I can have another category based on the vertical position of the tongue that they can be high vowel, (/i:/), in which the tongue is in the high position in the mouth. Mid vowel (/ə/), that the tongue is considered to be in the mid or middle position in the mouth finally the low vowels (/æ/), that the tongue is in the low position in the mouth. Therefore, the position of tongue is significantly important in order to produce a vowel, and the change in its position can vary the kind of vowel, but it's not easy to determine this change. In order to make it easy to understand, phoneticians could produce a diagram that has been called vowel chart (Figure 1). So, there are other vowel charts in which possessing some differences. In this chart you can see four rounded vowels which are selected for this study.

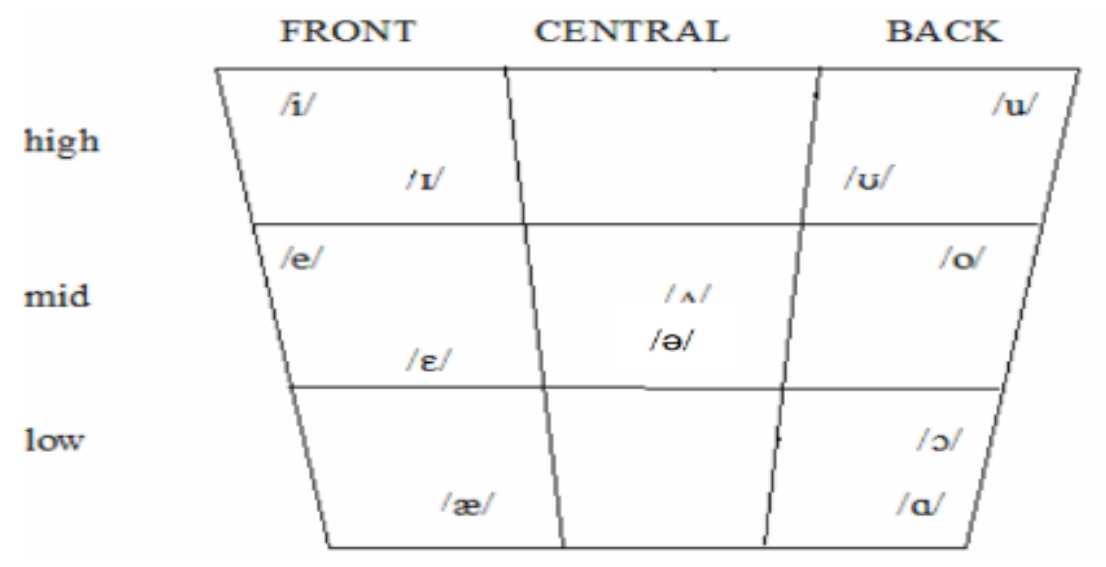

Figure 1. Vowel chart (Rauber, 2006, p. 23) 


\subsection{Experimental Background}

In a study, Busby and Plant (1995) selected forty pre-adolescents which divided into 20 boys and 20 girls in four groups of age: 5, 7, 9, and 11 years old. Actually, they were supposed to produce 11 Australian English vowels in which were non-diphthong and in a stressed syllable. Then their voices were recorded and also analyzed in order to measure F0, F1, F2, and F3 values. After accomplishment of process of measuring, it could be found that with increasing age, the F0, F1, F2, and F3 decrease simultaneously, with respect to this difference that F0 was the same for both boys and girls, on the contrary, F1, F2, and F3 for boys were in fact lower than those of girls.

Simpson and Ericsdotter (2003) examined if the size of F2xF1 vowel space can correlate with F0 or not. Actually, there were 17 males and 70 females from Germany as participants. Isolated words with structure of /hV:b(ə)/, containing long vowels /i:, e:, a:, $\mathrm{o:}, \mathrm{u}: /$, and ten short sentences from the Berlin sentence containing two short vowels $/ \varepsilon /$ and $/ \mathrm{J}: /$ were selected as the materials. Participants' sounds were recorded in a sound-treated room. Formant frequencies for both materials, and average F0 of the ten sentences were measured. At the end, the researchers found average F0 and the area of the individual vowel spaces for females were more than that of males', although the largest male areas had a certain amount of overlap with the smallest female areas. Average F0 and F1×F2 vowel space size correlation was highly significant for females.

Grepl, Furst, and Pesak (2007) tried to work on the Czech vowels /a, e, i:, o, u:/ and presented their formant chart. In fact, this study includes 35 students were selected from Pedagogical Faculty of Palacky University. They pronounced those vowels, not only their sounds were recorded but also analyzed by digital methods. Next, both the first and the second formants of each vowel for each individual-participant were achieved, then their formant chart were drowned. Finally, results could indicate the frequency bands of $\mathrm{F} 1$ for vowels were as follows: From 850 to $1150 \mathrm{~Hz}$ for vowel /a/, from 700 to $950 \mathrm{~Hz}$, for vowel /e/, from 300 to $450 \mathrm{~Hz}$ for vowel /i:/, From 600 to $800 \mathrm{~Hz}$ for vowel/o/, and from 100 to $400 \mathrm{~Hz}$ for vowel /u: , and also frequency bands of F2 for them were as follows: for vowel /a/, from 1200 to $2000 \mathrm{~Hz}$, for vowel /e/, from1700 to $3000 \mathrm{~Hz}$, for vowel /i:/, from 2000 to $3600 \mathrm{~Hz}$, for vowel /o/, from 600 to $1400 \mathrm{~Hz}$, and for vowel /u:/ from 400 to $1200 \mathrm{~Hz}$.

Xia (2013) worked on gender differences in language with regard to differences in their pronunciation, intonation, vocabulary, syntax, manners, attitudes, and in addition, in non-verbal differences. He could also examine the changes of these differences all over the time. According to Xia (2013), all of these differences and their changes were covered in that study. Therefore, the results represented that the differences changed during time. Besides, the development of the society decreased these changes. And additionally, more participation in social activities could cause other changes in future. This study also showed women's social status is improved by passing time.

Hisham (2014) carried out a study in which included 3 Broca's aphasia and 3 normal speakers as participant. In fact, they were right-handed with age between 49 to 58 years. He measured and analyze short Arabic vowels which including (/l/, /a/, /u/) in order to find their durations. Besides, the syllable structure was (CVC). to find whether voicing affected vowel duration or not, these vowels were followed by the voiced fricative /z/ and the voiceless fricative /s/. Each participant produced each vowel 6 times, then their voices were recorded. Accordingly, in a silent place and via PRAAT software, the recording process could be done. The study demonstrated for all participants' vowels which followed voiced fricatives became longer. In Broca's aphasic speakers' speech, vowel durations were greater than that of normal speakers. In normal speakers, the short vowel /u / had shorter durations compared to high front vowel ///. On the other hand, it had longer duration, in Broca's aphasic speakers' speech. Accordingly, in Broca's aphasic speakers compared to the normal speakers, the vowel /a/ had shorter duration. Finally, in both groups, the low vowel /a/ had the longest duration in comparison with /l/ and /u/.

\section{Research Questions}

The following questions were posed in this study:

RQ1. Are gender differences in Iranian speakers to produce rounded vowels compatible with gender differences in English speakers to produce rounded vowels?

RQ2. Do Persian speakers produce English rounded vowels different from those produced by native English speakers?

\section{Method \\ 4.1 Participants}

The participants in this study were 60 Iranian EFL learners with age range of 6 to 25, accordingly, they were 30 males and 30 females from Iran. They were at elementary and intermediate levels, actually their level was determined by Oxford placement test (2001). All the participants spoke the same language and they had not any brain injuries, hearing or visual problems that interfered with their performance in the test. 
It should be noted that the researcher had no access to native speakers so, he could not select native participants. Therefore, to compare Iranian EFL learners with native speakers, the researcher compiled their data by resorting to the previous studies. In other words, the data of the native speakers were collected by reading the previous studies. We can say that the data of the native speakers were corpus-based.

\subsection{Instruments}

In the present study, five instruments were applied. The first one was Oxford proficiency test (OPT, 2001) which was used to make sure that the learners were totally homogenous with regard to their English proficiency level.

The second instrument used was Bandlab, an application in order to record voices on mobile phone with high quality and also was available for both IOS and Android operating system. The third instrument was WhatsApp Messenger, or simply WhatsApp, is an American freeware, cross-platform messaging and Voice over IP service owned by Facebook, Inc. It allows users to send text messages and voice messages, make voice and video calls, and share images, documents, user locations, and other media.

The fourth and last instrument, was PRAAT software (win 64). In fact, "Praat" is a Dutch word which means "speak" or "talk". Via PRAAT software we can analyze speech sounds in phonetics, PRAAT is also available on the internet for free. Phonograph (invented by Thomas Edison) was the first device that made the recording and reproduction of sounds possible. As a matter of fact, by this invention, speech sounds could be heard repeatedly and then they could be analyzed. PRAAT can be called one of the most popular devices between these devices which is widely used by researchers to launch acoustic analysis. The fifth instrument was Excel of Microsoft office package which was used in order to make figures and diagrams to make exclusive pattern producing of each Iranian and American group of male and female.

\subsection{Materials}

Four words with CVC syllable structure were selected from oxford dictionary which then participants made sentence in the structure of for example, "say hood please". In addition, these words containing rounded vowels. In Persian there are three round vowels /a/, /O/ and /u/ and in English there are four round vowels /u:/, / / /, / :/ and /o/ (Birjandi \& Salmani-Nodoushan, 2005), but this study only tried to focus on rounded vowels which containing $/ \mathrm{u}: /, / \mathrm{J} /, \mathrm{J}: /$ and $/ \mathrm{O} /$. The reason for choosing only these vowels was because they are similar in some features and the purpose was to investigate whether this similarity will cause male and female produce them the same or not, and actually they were selected based on a study which was done in Iranian context on Persian vowels $/ u /$ and $/ J /(S h e k a r a m i z, 2014)$, and now this study aimed to see whether the findings of that study will be similar to the results obtained.

\subsection{Procedure}

To do this research, 30 males and 30 females from Iranian EFL learners with age range between 6 and 25 at elementary and intermediate levels were selected. Then four words containing round vowels $/ \mathrm{u}: /, / \mathrm{v} /, \mathrm{J}: /$ and /D/ with CVC syllable structure from Oxford dictionary were selected. The words were put inside the carrier sentence "Say......please". Process of data-collecting was done in some boys and girls from different institutes through online messenger. Additionally, through this application, the researcher was able to observe the process by video call which was available on WhatsApp. Then after doing the test, the learners who were right-handed with no brain injuries and also were between 6 and 20, hearing or visual problems were selected, among them, 60 learners who were eager to participate in this study started the tasks in next online sessions. The researcher explained about the task and about how the participants had to perform in the recording process, for example, they needed to be silent, during recording process, and when it was stopped they would be aware by moving the researcher's hand, sentences were needed to be produced clearly and naturally, and they were supposed to be read separately one by one because the sound of each sentence was needed to be recorded and saved separately via bandlab. Therefore, after the production of a sentence, they learners had to stop and send researcher the voices which was recorded by bandlab and then the researcher saved the produced sound. Then each learner was asked to participate in video-call one by one and read the sentences which were sent through personal message before making video-call. After that, the learners were asked to utter the carrier sentences and their voices were recorded.

Note; the process of sending files was held via three professional apps, such as bandlab, telegram and WhatsApp.

A pilot study was already done on 10 participants ( 5 males and 5 females) in order for the researcher to get familiar with using PRAAT software and find the subjects' epenthesis cases in spectrograms.

Actually, recording was done via PRAAT software (win 64).

When PRAAT is run, a window is shown. On the left, there is the PRAAT objects window. In this window, you can either record or load a prior saved sound, then the sound recorded window will be shown (Figure 2).

Finally, the recorded sound was saved for later analyses. 


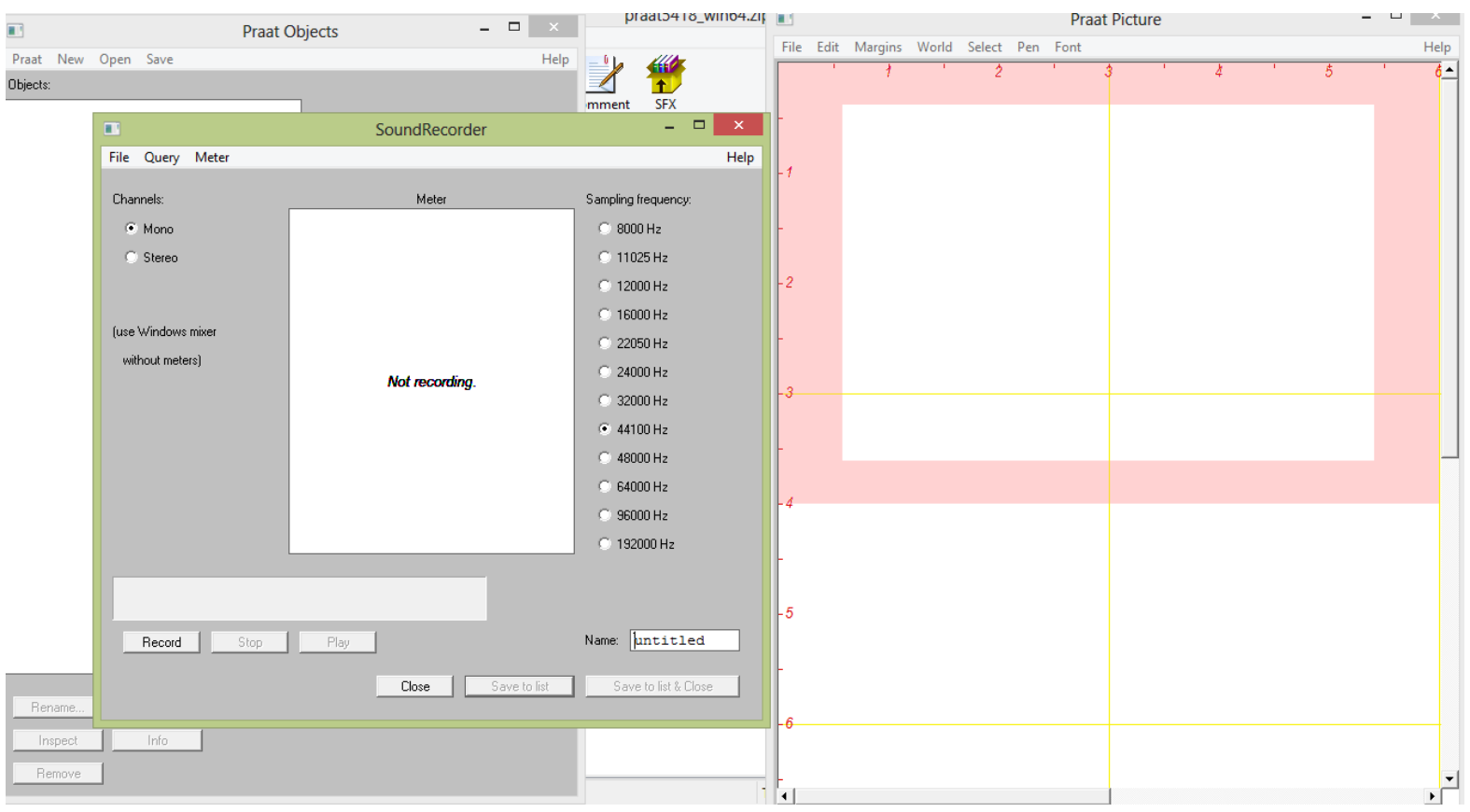

Figure 2. The first window of PRAAT software

In order to analyzing a sound, its file was put in the list by clicking on the 'Open' option on the timeline and in fact on top of the software between the 'New' and 'Save', then the option 'Open long sound file ' or 'Read from file' was selected from the opened list. After that, the file which contained the saved sounds was found and added to list, the desired sound file was selected and 'Open' option at the bottom of the opened file was clicked on.

After selecting the 'View and Edit' option the spectrogram of the recorded sound was shown. In the spectrograms, dark bands represent the Formants, $x$-axis illustrates time and $y$-axis represents frequencies. By clicking on the horizontal bands below the spectrogram the recorded sounds were played. To recognize a part of the spectrogram, it was done several times which contained the desired vowel. Then that part was selected by dragging the indicator of mouse on that. After that, the sound of that $p$ art should be played again to see if it only contained the vowel or not, this procedure must be repeated until the part which only contained the desired vowel was found (Figure 3).

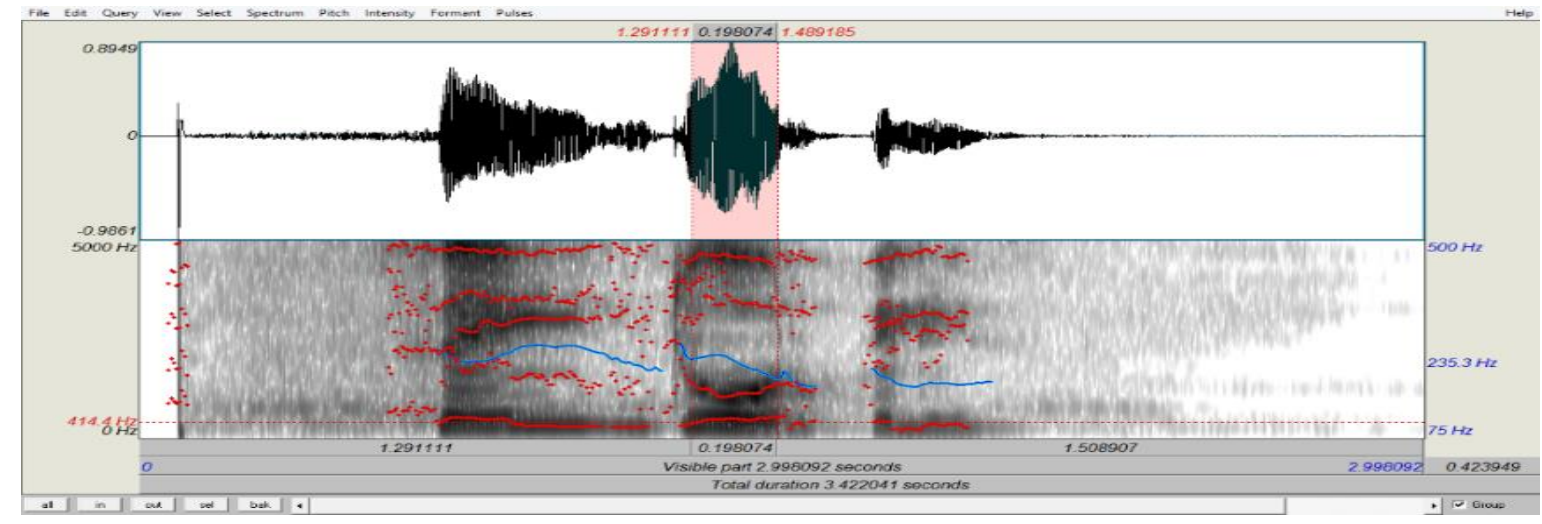

Figure 3. A selected vowel in a spectrogram

By pressing on 'sel' option, the spectrogram of that selected part could be shown, then by looking at it precisely, its center was recognized visually and clicked on. Finally, by choosing the option 'Formant option' which is located inside the timeline, on top of the software and selecting 'Formant listing', the F1, F2 and F3 of that vowel were shown (Figure 4). In the figure below, F1 and F2 for round vowel /o/ of the word "hoed" in the sentence "Say hoed please" produced by the researcher is demonstrated. As can be seen, F1 and F2 of this vowel were 699.09127 and 1076.482030 respectively which produced by a man. All the obtained F1s and F2s were recorded on a prepared chart. 


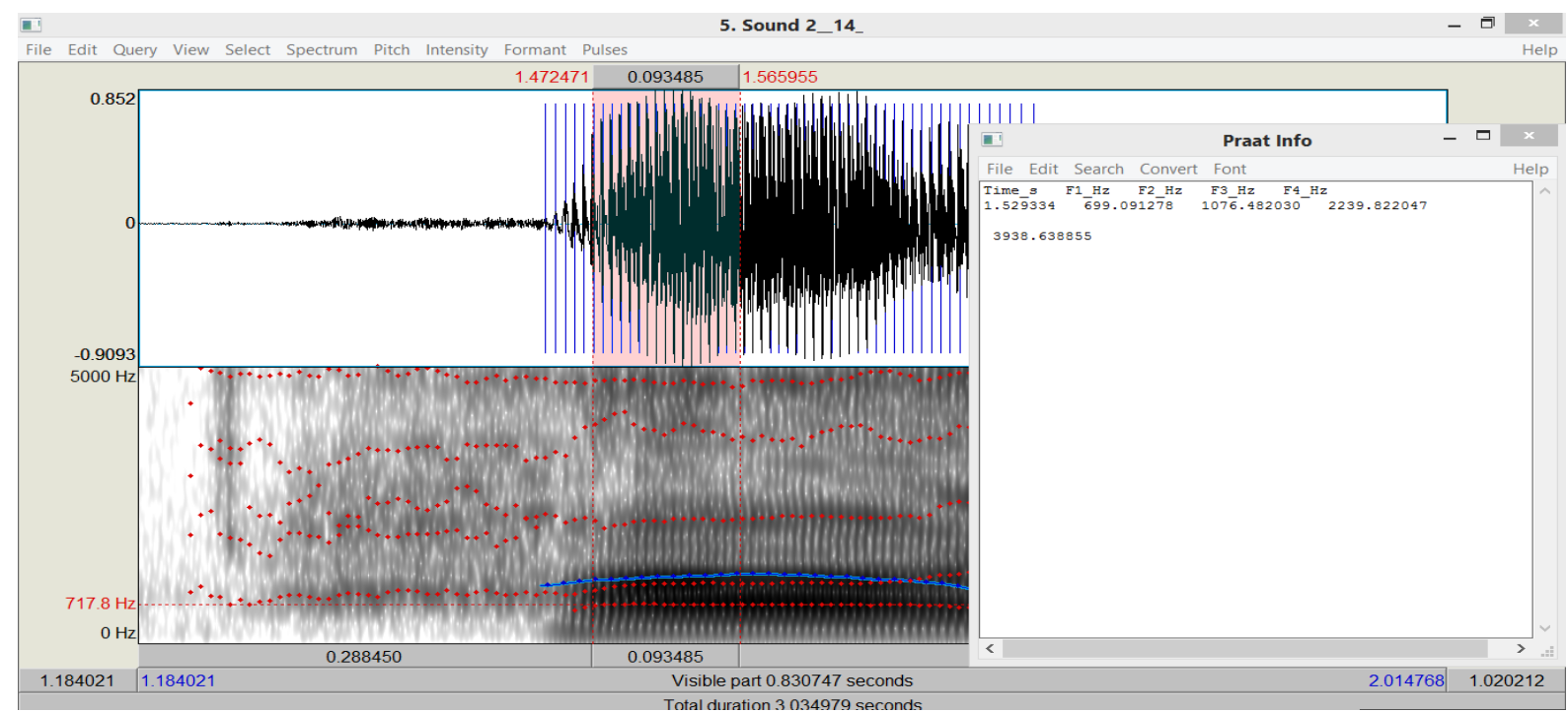

Figure 4. Horizontal dark lines which are F1 and F2 of the selected part

After accomplishment of these procedures which has been mentioned above, the vowel diagrams for both male and female were drawn according to their averages which the researcher obtained via all produced sentences, collecting data and finally by having the amounts of F1 and F2 of each vowel. In above diagram the x-axis represented F2 and the $y$-axis represented F1.

\subsection{Data Analysis}

Via PRAAT software, first, all voices of participants were recorded and analyzed in order to obtain F1 and F2 of each vowel which were produced by each participant indeed, second, their averages became collected, the vowel points of F1 and F2 for male and female were appeared on vowel diagram, then, the received data from male and female speeches were compared to each other in order to find their existing differences, finally, the data were put in excel in order to make patterns and diagrams of vowel dots and their exclusive shapes.

\section{Results}

In order to compare male's and female's production of the English round vowels it was considered to be essential to have their F1s and F2s, so we obtained them by PRATT software. Tables 1 to 4 illustrate the obtained F1s and F2s of these vowels:

Table 1: Iranian F1s of the rounded vowels from males' productions

\begin{tabular}{ccccc}
\hline Participant & Who'd & Hood & hoed & Horde \\
\hline 1 & 383 & 551 & 675 & $\mathbf{4 4 7}$ \\
\hline 2 & 346 & 470 & 697 & $\mathbf{4 2 5}$ \\
\hline 3 & 421 & 524 & 666 & $\mathbf{4 8 4}$ \\
\hline 4 & 357 & 515 & 698 & $\mathbf{5 7 2}$ \\
\hline 5 & 436 & 499 & 659 & $\mathbf{4 3 4}$ \\
\hline 6 & 381 & 483 & 743 & $\mathbf{4 9 3}$ \\
\hline 7 & 369 & 517 & 791 & $\mathbf{4 7 7}$ \\
\hline 8 & 364 & 509 & 609 & $\mathbf{5 2 8}$ \\
\hline 9 & 354 & 454 & 587 & $\mathbf{5 1 4}$ \\
\hline 10 & 348 & 463 & 664 & $\mathbf{6 5 5}$ \\
\hline 11 & 463 & 790 & 708 & $\mathbf{5 8 0}$ \\
\hline 12 & 346 & 435 & 664 & $\mathbf{5 9 8}$ \\
\hline 13 & 352 & 469 & 785 & $\mathbf{4 4 8}$ \\
\hline 15 & 348 & 382 & 780 & $\mathbf{5 2 9}$ \\
\hline
\end{tabular}




\begin{tabular}{|c|c|c|c|c|}
\hline 16 & 535 & 422 & 788 & 501 \\
\hline 17 & 307 & 467 & 718 & 499 \\
\hline 18 & 357 & 396 & 673 & 453 \\
\hline 19 & 332 & 558 & 676 & 467 \\
\hline 20 & 346 & 430 & 808 & 528 \\
\hline 21 & 429 & 436 & 940 & 482 \\
\hline 22 & 324 & 481 & 649 & 442 \\
\hline 23 & 337 & 592 & 683 & 436 \\
\hline 24 & 307 & 598 & 833 & 528 \\
\hline 25 & 340 & 561 & 779 & 645 \\
\hline 26 & 279 & 478 & 861 & 497 \\
\hline 27 & 443 & 494 & 479 & 537 \\
\hline 28 & 290 & 483 & 654 & 566 \\
\hline 29 & 301 & 646 & 813 & 519 \\
\hline 30 & 327 & 446 & 724 & 537 \\
\hline
\end{tabular}

Table 2: Iranian F2s of the rounded vowels from males' productions

\begin{tabular}{|c|c|c|c|c|}
\hline Participant & Who'd & Hood & hoed & Horde \\
\hline 1 & 1278 & 917 & 1068 & 762 \\
\hline 2 & 1082 & 840 & 1075 & 947 \\
\hline 3 & 720 & 910 & 1128 & 844 \\
\hline 4 & 848 & 827 & 1098 & 831 \\
\hline 5 & 852 & 863 & 969 & 704 \\
\hline 6 & 1151 & 803 & 1023 & 771 \\
\hline 7 & 1117 & 1030 & 1243 & 875 \\
\hline 8 & 640 & 922 & 933 & 815 \\
\hline 9 & 1643 & 973 & 1008 & 555 \\
\hline 10 & 1104 & 724 & 995 & 1003 \\
\hline 11 & 2238 & 2487 & 1192 & 634 \\
\hline 12 & 1069 & 693 & 985 & 955 \\
\hline 13 & 1106 & 1220 & 1095 & 873 \\
\hline 14 & 877 & 769 & 1048 & 1102 \\
\hline 15 & 764 & 777 & 1016 & 2288 \\
\hline 16 & 2446 & 1388 & 1057 & 836 \\
\hline 17 & 2426 & 861 & 1042 & 520 \\
\hline 18 & 743 & 816 & 1071 & 1299 \\
\hline 19 & 913 & 1246 & 1234 & 783 \\
\hline 20 & 1260 & 941 & 1127 & 660 \\
\hline 21 & 1035 & 1503 & 1242 & 814 \\
\hline 22 & 714 & 1131 & 1101 & 476 \\
\hline 23 & 1373 & 2629 & 1157 & 958 \\
\hline 24 & 1452 & 834 & 953 & 984 \\
\hline
\end{tabular}




\begin{tabular}{ccccc}
\hline 25 & 919 & 2727 & 1072 & $\mathbf{1 0 7 5}$ \\
\hline 26 & 1380 & 805 & 1133 & $\mathbf{7 7 4}$ \\
\hline 27 & 963 & 911 & 807 & $\mathbf{8 2 8}$ \\
\hline 28 & 1796 & 1006 & 1801 & $\mathbf{9 1 4}$ \\
\hline 29 & 1161 & 2681 & 2272 & $\mathbf{7 7 4}$ \\
\hline 30 & 2266 & 900 & 1026 & $\mathbf{6 9 8}$
\end{tabular}

Table 3: Iranian F1s of the rounded vowels from females' productions

\begin{tabular}{|c|c|c|c|c|}
\hline Participant & Who'd & Hood & hoed & Horde \\
\hline 1 & 316 & 590 & 902 & 518 \\
\hline 2 & 343 & 453 & 959 & 519 \\
\hline 3 & 500 & 484 & 818 & 513 \\
\hline 4 & 380 & 766 & 1086 & 677 \\
\hline 5 & 371 & 561 & 978 & 568 \\
\hline 6 & 356 & 560 & 797 & 487 \\
\hline 7 & 428 & 537 & 860 & 531 \\
\hline 8 & 490 & 604 & 779 & 553 \\
\hline 9 & 449 & 583 & 1020 & 651 \\
\hline 10 & 455 & 675 & 842 & 521 \\
\hline 11 & 503 & 515 & 699 & 552 \\
\hline 12 & 310 & 513 & 909 & 537 \\
\hline 13 & 423 & 541 & 899 & 559 \\
\hline 14 & 366 & 485 & 848 & 530 \\
\hline 15 & 491 & 522 & 821 & 564 \\
\hline 16 & 588 & 658 & 627 & 698 \\
\hline 17 & 356 & 613 & 860 & 889 \\
\hline 18 & 753 & 656 & 722 & 548 \\
\hline 19 & 353 & 564 & 606 & 648 \\
\hline 20 & 595 & 610 & 849 & 524 \\
\hline 21 & 321 & 745 & 924 & 483 \\
\hline 22 & 505 & 590 & 795 & 613 \\
\hline 23 & 430 & 554 & 940 & 568 \\
\hline 24 & 395 & 617 & 813 & 589 \\
\hline 25 & 509 & 514 & 871 & 568 \\
\hline 26 & 456 & 596 & 861 & 774 \\
\hline 27 & 353 & 579 & 836 & 451 \\
\hline 28 & 476 & 490 & 700 & 604 \\
\hline 29 & 371 & 590 & 1090 & 497 \\
\hline 30 & 483 & 542 & 950 & 491 \\
\hline
\end{tabular}


Table 4: Iranian F2s of the round vowels from females' productions

\begin{tabular}{|c|c|c|c|c|}
\hline Participant & Who'd & Hood & hoed & Horde \\
\hline 1 & 1142 & 1047 & 1500 & 1010 \\
\hline 2 & 662 & 831 & 1271 & 804 \\
\hline 3 & 849 & 955 & 1375 & 980 \\
\hline 4 & 732 & 1016 & 1304 & 848 \\
\hline 5 & 981 & 979 & 1280 & 867 \\
\hline 6 & 930 & 1141 & 1213 & 992 \\
\hline 7 & 894 & 929 & 1232 & 948 \\
\hline 8 & 1402 & 938 & 1200 & 845 \\
\hline 9 & 1108 & 919 & 1297 & 917 \\
\hline 10 & 1410 & 1120 & 1310 & 1016 \\
\hline 11 & 1126 & 1166 & 1013 & 1193 \\
\hline 12 & 909 & 1047 & 1110 & 1050 \\
\hline 13 & 936 & 828 & 1351 & 854 \\
\hline 14 & 1218 & 945 & 1433 & 914 \\
\hline 15 & 1741 & 1007 & 1133 & 1329 \\
\hline 16 & 1214 & 1168 & 1004 & 971 \\
\hline 17 & 753 & 969 & 1202 & 976 \\
\hline 18 & 1533 & 1035 & 1001 & 1032 \\
\hline 19 & 960 & 994 & 1081 & 1228 \\
\hline 20 & 1212 & 1168 & 1212 & 892 \\
\hline 21 & 858 & 816 & 1369 & 830 \\
\hline 22 & 1310 & 921 & 1131 & 945 \\
\hline 23 & 1265 & 802 & 1218 & 670 \\
\hline 24 & 907 & 926 & 1162 & 962 \\
\hline 25 & 1136 & 981 & 1337 & 846 \\
\hline 26 & 994 & 936 & 1295 & 1200 \\
\hline 27 & 982 & 921 & 1261 & 739 \\
\hline 28 & 1334 & 752 & 933 & 667 \\
\hline 29 & 908 & 918 & 1876 & 735 \\
\hline 30 & 1193 & 752 & 1364 & 762 \\
\hline
\end{tabular}

Table 5 demonstrates male's and female's mean F1s and F2s of rounded vowels in the words" who'd, hood, hoed, and horde "

Table 5: Iranian Male's and Iranian female's mean F1s and F2s of rounded vowels

\begin{tabular}{|c|c|c|c|c|c|}
\hline & & Who'd /u:/ & $\begin{array}{l}\text { Hood } \\
\text { /v:/ }\end{array}$ & $\begin{array}{l}\text { hoed } \\
\text { /o:/ }\end{array}$ & $\begin{array}{l}\text { Horde } \\
\text { /১:/ }\end{array}$ \\
\hline \multirow[t]{2}{*}{ Male (mean) } & $\mathrm{F} 1$ & 361 & 498 & 717 & 507 \\
\hline & $\mathrm{F} 2$ & 1246 & 1171 & 1132 & 875 \\
\hline \multirow[t]{2}{*}{ Female (mean) } & $\mathrm{F} 1$ & 437 & 560 & 855 & 574 \\
\hline & $\mathrm{F} 2$ & 1086 & 964 & 1248 & 934 \\
\hline
\end{tabular}


As can be seen in Table 5, for rounded vowels the highest mean F1 and F2 were as follows: In males: the highest mean F1 $\rightarrow$ " hoed and rule" (717) , the highest mean F2 $\rightarrow$ "who'd" (1246) In females: the highest mean F1 $\rightarrow$ " hoed " (855) , the highest mean F2 $\rightarrow$ " hoed " (1248)

Also, the table shows that the lowest mean F1 and F2 for rounded vowels were as follows:

In males: the lowest mean F1 $\rightarrow$ "who'd" (361) , the lowest mean F2 $\rightarrow$ "horde" (875)

In females: the lowest mean F1 $\rightarrow$ "who'd" (437) , t the lowest mean F2 $\rightarrow$ "horde" (934)

According to focused data which are reported above, we could find out an astonishing result which addressed that Iranian females own higher F1 compared to Iranian males. However, Iranian males own higher F2 in producing the vowels including (/ $\mho /$ and / $\mathrm{u} /$ ) sounds. Nevertheless, American females produce both higher F1 and F2 than Iranian ones.

Table 6: Male's and female's mean F1 and F2 of rounded vowels

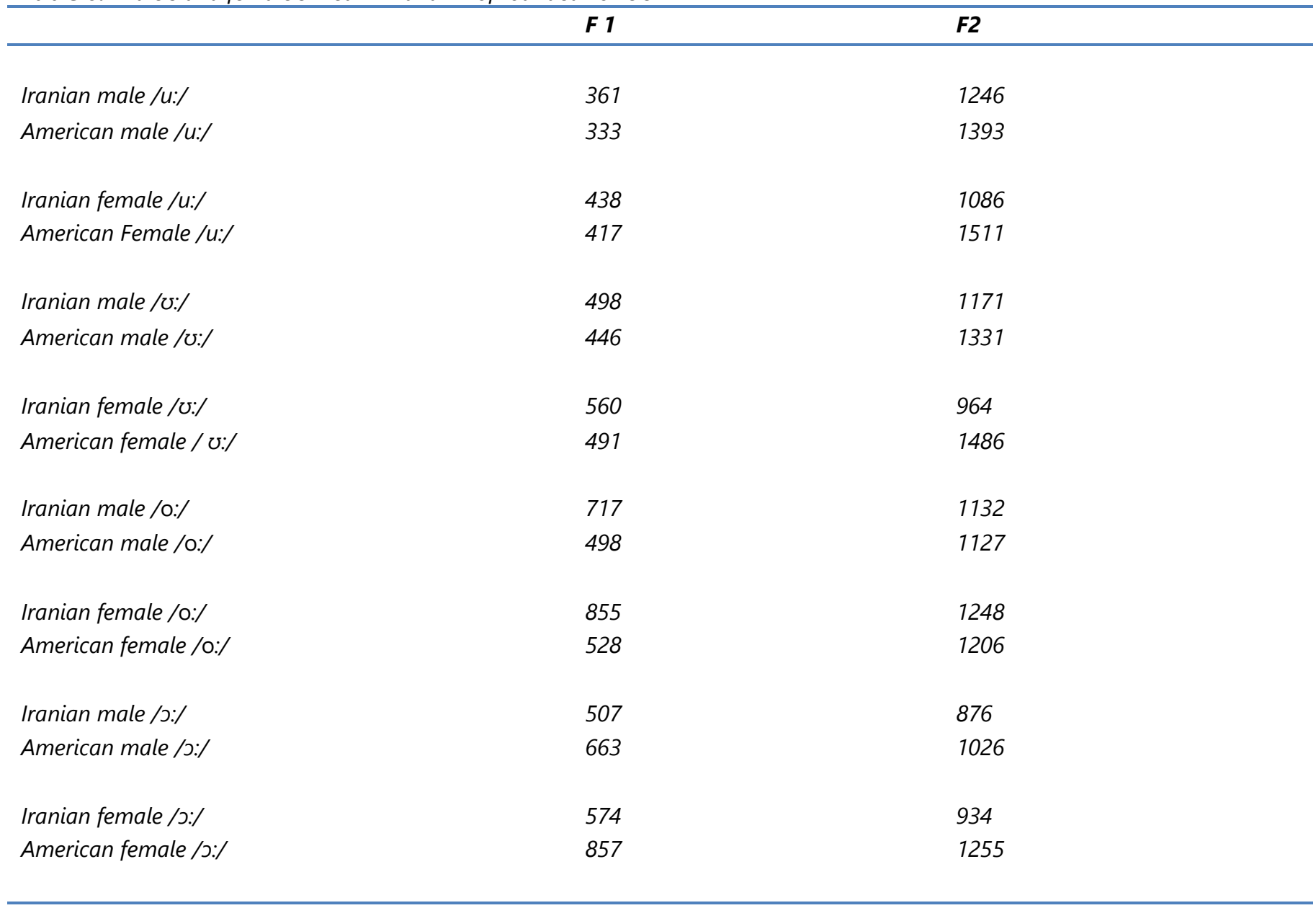

The Table 6 shows results which are in contrast to the previously reported data indicating that females'

formant frequencies are higher than those of males. As can be seen, all mean F1s are parallel to data reported in the previous studies; formant frequencies are higher in female speech compared to that of male. But F2 in producing two vowels including (/v:/ and /u:/) means are in contrast to that previously reported finding.

Also, according to Table 6:

For Iranian: $\left\{\begin{array}{c}\text { Mean F2 of male vowel /u:/ (1246) > mean F2 of female vowel /u:/ (1086) } \\ \text { Mean F2 of male vowel /U:/ (1171) > mean F2 of female vowel / :/ (964) }\end{array}\right.$ 
Reviewing all tables so far indicates that in both two rounded vowels (/u:/ and / $:$ :), \%50 of males' mean F2s were higher than females' mean F2s. This result violated the pattern reported by other researchers (e.g. Fant, 1970) that females' frequencies of vowels are higher than those of males.

Drawing the vowel points of the rounded vowels for both Iranian and American male and female represent the different patterns of producing which are existing between American and Iran with respect to genders. Actually the figure indicates that the pattern of producing rounded vowels in English words which are pronounced by Iranian EFL learners (speakers) are completely different from the pattern of American speakers, on the other hand the Iranian speakers (both male and female) produce somewhat same patterns in comparison with each other and also, American speakers produce somewhat same pattern in comparison with each other, perhaps with a very slight difference in measures.

Figure 8. Vowel dots and lines for American female.

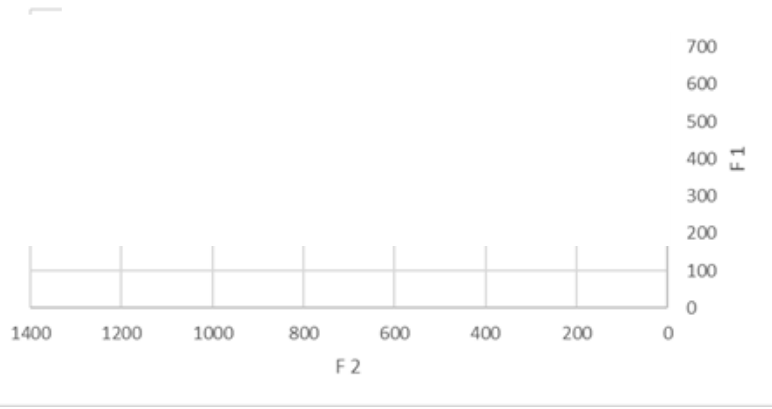

Figure 5. Vowel dots and lines for Iranian male

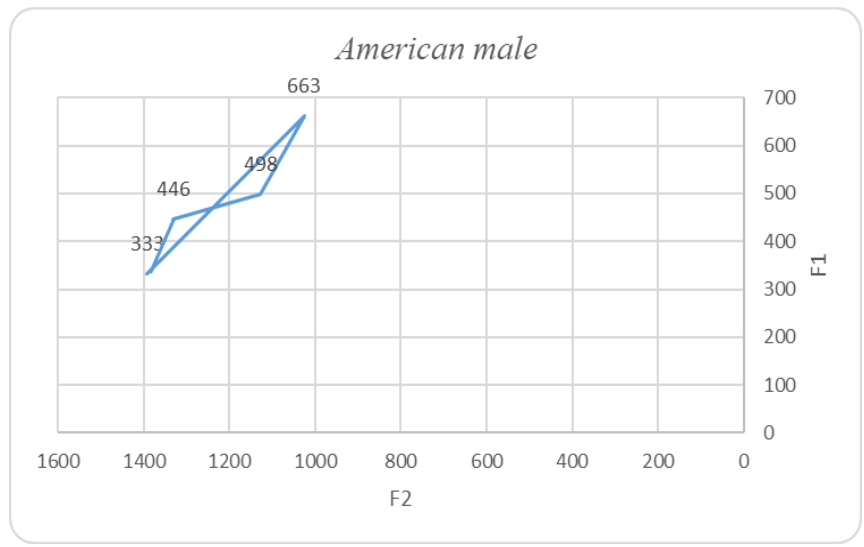

Figure 7. Vowel dots and lines for American male
Iranian Female

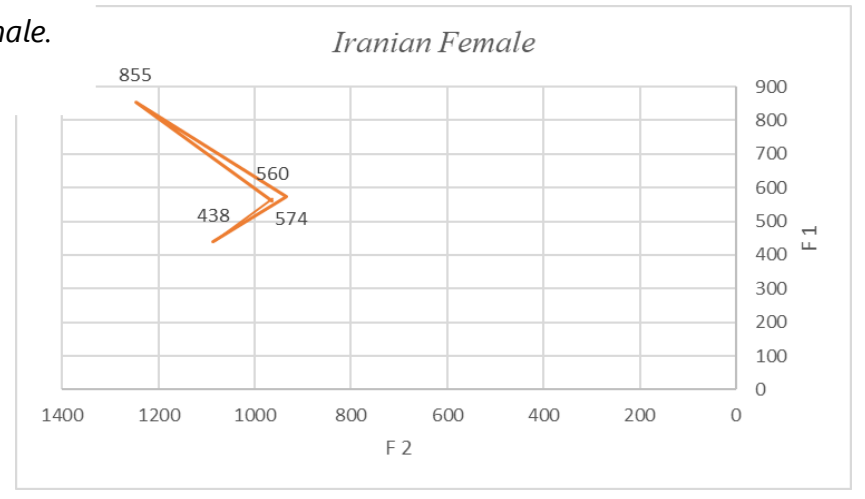

Figure 6. Vowel dots and lines for Iranian female

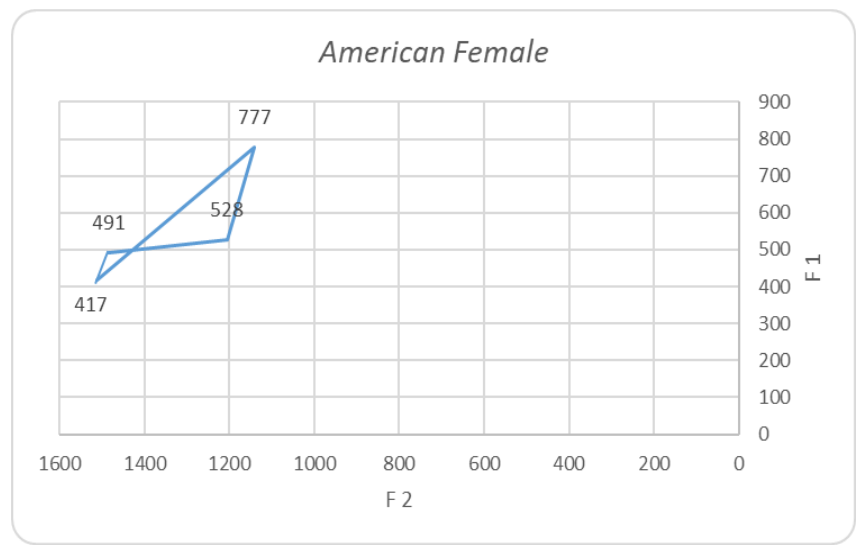

Figure 8. Vowel dots and lines for American female

\section{Discussion}

The overall purpose of the current study was to investigate gender differences between Iranian EFL learners and American people in producing all English rounded vowels. For doing this, the F1 and F2 of these two vowels of male's and female's speech were obtained and compared to find the differences.

Based on the results, for Iranian speakers, the highest means F1 of both male and female belong to the word " hoed " /o:/, and also the highest mean F2 of male was in the word "who'd" /u:/ and the highest mean F2 of female was in the word " hoed "/o:/.

Accordingly, for American speakers, the highest mean F1 of male belongs to the word "hawed"/د:/, and for female belongs to the word " hoed "/o:/, and the highest mean F2 of both male and female was in the word "who'd"/u:/. 
We measured the and maximum formant frequency values in order to determine whether the preceding and following consonants influence the values of F1 and F2; according to results, in F1 values, no gender differences were seen considering the consonantal context. in contrast, the maximum and minimum values of $\mathrm{F} 2$ were found in different words for male and female; it illustrates that in F2 values, there are gender differences considering the consonantal context. In Iranian speakers, F2s of the two rounded vowels including (/u:/ and / $/: /)$ show gender differences in this regard.

According to the findings, for Iranian speakers, for male the mean F2s of vowel /u:/ and vowel / $v: /$ were higher than Iranian female. in conclusion, F2s of these two rounded vowels shows gender differences in this regard too.

As it was mentioned previously, F2 indicates the degree of backness, in front vowels, F2 owns higher frequency. However, in back vowels it has lower frequency. Therefore, in this study with respect to the results, in male the degrees of backness of vowel /u:/ and vowel / $\mathrm{v} /$ were less than that of women. But in American speakers they were reverse, so F2s of the two rounded vowels which produced by Iranian show gender differences in this regard too.

Regarding the firs research question "Are gender differences in Persian vowels compatible with gender and differences in English vowels?, the results showed that for Iranian speakers, the comparison which has been carried out between the male mean F1 and F2 and female mean F1 and F2 of the all English vowels represent that male means F1 of these vowels were lower than those of female (which is similar to the results reported in previous studies such as Busby and Plant (1995). On the other hand, as mentioned above, male mean F2 was higher than the mean F2 of two vowels in female (which was in contrast to the results reported in previous studies indeed). As the mean F2 was higher in male in producing two vowels, it indicates the degree of backness of the two vowels in male were less than female. These finding are consistent with results reported by Shekaramiz (2014) in which male's mean F2 of vowels / $\mathrm{u}$ :/ than that of female, and in consistent with results obtained by Busby and Plant (1995).

According to the results, Iranian male and female diagrams are similar to each other and also American speaker diagrams followed a same pattern in comparison with each other, so the represented differences which have been mentioned previously imply that there is no gender differences in producing vowels pronunciation between Iranian speakers and native speakers, thus the present differences are due to the language differences, as you can see Iranian male and female could produce a somewhat similar pattern and the same is true for American speakers. Although there is a difference in pronouncing vowels (/u:/ and / $\mathrm{v} / /)$ between Iranian male and female, their figures illustrate that the difference is not huge, and furthermore, study also showed that formant frequencies are affected by gender. This result is not in line with results of the studies by Günzburger, Bresser, and Ter Keurs (1987), because according to their studies gender did not affect the formant frequencies. In contrast, in the study conducted by Nittrouer et al. (1990), it was found that gender affected acoustic parameters.

Regarding the second research question" Do Persian speakers produce English rounded vowels different from those produced by native English speakers? the vowel diagram showed no specific differences between male and female. On the other hand, languages variation resulted in the different shape of producing vowels and pronouncing them. The findings of this study and other similar studies reveal that comparing male and female, and in this study comparison between Iranian speakers and native ones in producing vowels gives different results in different studies, it might be due to the different factors such as age, level of proficiency and place can affect this issue.

\section{Implications and Conclusions of the Study}

Pronunciation of English Rounded vowels are significantly important to know in order to speak English fluently and correctly indeed, so we as English instructors must be aware of possible differences while we are teaching English to our students.

Needless to say, English and Persian languages have many differences and these differences lead to many pronunciation errors for Persian learners of English, therefore English teachers should worry about how to teach their students in order to achieve good and native-like pronunciation. Acoustic studies can be considered to be one way which can be used in learning a English language pronunciation, actually the formant frequencies which were obtained in acoustic studies can give some information about what learners pronounce, for instance, pitch, the degree of backness, etc. So, it is possible to realize if their pronunciation is correct or not, teachers can try to solve it.

It's apparently obvious that the results of this study also include pedagogical implications for teaching English diphthongs and triphthongs. Birjandi and Salmani-Nodoushan (2005) say "Diphthongs are those sounds that consist of a movement or glide from one vowel to another" (p. 63) and "Triphthongs are those sounds that consist of a movement or glide from one vowel to

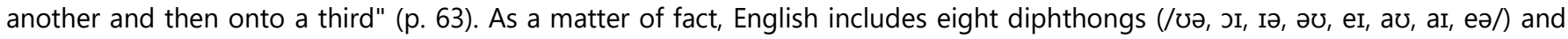

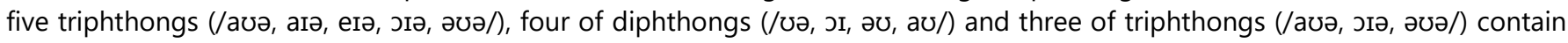


round vowels / / / or / / (Birjandi \& Salmani-Nodoushan, 2005; Namaziandost, \& Çakmak, 2020). Thus, the differences that could be discussed in this study between male and female in producing all English round vowels can be contributed to producing diphthongs and triphthongs. Therefore, we are able to call this study as a helpful investigation in teaching them.

The results of this study can mainly be used in teaching English rounded vowels. Although differences are vivid between American natives and Iranian EFL learners in producing English rounded vowels, we as teachers can put best effort into teaching correct vowels. For instance, $/ \mathrm{u}: /$ is a tense and $/ \mathrm{v} /$ is a lax vowel. In producing lax vowels, the tongue is in the position relatively lower than that of tense vowels (Keshavarz, 2003). Also, various meaning can be led from vowels, for example /u:/ in " too " (/tu:/) means more than is needed or wanted; more than is suitable or enough, and / ə / in "to" (/tə /) which is a preposition and furthermore, /u:/ in "fool" (/fu:l/) means stupid, and / $\mho /$ in "full" (/fol/) means ample or laden. Actually, Persian learners are not completely aware of these kinds of differences, so in pronouncing vowels and rounded vowels in particular, they make errors, because they can't recognize correctly how to use /u:/ and how to use / $\mho /$.

The current study tried to demonstrate gender differences in producing all English rounded vowels, thus the results can also be used in classes which include only one gender, by doing so, teachers can get better results while they're teaching pronunciation, since issues which are affected by gender, are better to be taught in single-sex classes in order to achieve better results indeed.

\section{References}

[1] Birjandi, P., \& Salmani- Nodoushan, M.A. (2005). An introduction to phonetics. Tehran, Iran: Zabankadeh publications.

[2] Busby, P. A., \& Plant, G. L. (1995). Formant frequency values of vowels produced bypreadolescent boys and girls. The Journal of the Acoustical Society of America, 97(4), 2603-6.

[3] Fant, G. (1970). Acoustic theory of speech production. Paris. Printed in The Netherlands by Mouton \& Co. N. V., Publishers.

[4] Fry, D. B. (2009). Acoustic phonetics: A course of basic readings. New York: Cambridge University Press.

[5] Grepl, M., Furst, T., \& Pesak, J. (2007). The F1-F2 vowel chart for Czech whispered vowels a, e, i, o, u. Faculty of Science, Palacky University, Olomouc.

[6] Günzburger, D., Bresser, A., \& Ter Keurs, M. (1987). Voice identification of prepubertal boys and girls by normally sighted and visually handicapped subjects. Language and Speech, 30(1), 47-58.

[7] Hillenbrand J., Getty L. A., Clark, M. J., \& Wheeler, K. (1995). Acoustic characteristics of American English vowels. Journal of the Acoustical Society of America, 97, 3099-3111.

[8] Hisham, A. (2014). Acoustical analysis of vowel duration in Palestinian Arabic speaking aphasics. American Journal of Psychiatry and Neuroscience, 2 (1), 13-17.

[9] Holmes, J. (1992). An introduction to sociolinguistics. University of New England: Diana Eades.

[10] Jongman, A. (2013). Acoustic phonetics. Oxford Bibliographies in Linguistics, New York: Oxford University Press.

[11] Labov, W. (2001). Principles of linguistic change: Vol. II: Social Factors. Oxford: Blackwell.

[12] Ladefoged, P. (1996). Elements of acoustic phonetics. Chicago: The University of Chicago Press.

[13] Ladefoged, P., \& Ferrari Disner, S. (2012). Vowels and consonants. Hoboken, NJ: Wiley- Blackwell.

[14] Namaziandost E., \& Shafiee, S. (2018). Gender differences in the use of lexical hedges in academic spoken language among Iranian EFL learners: a comparative study. International Journal of Research in English Education, 3(4), 64-80.

[15] Namaziandost, E., \& Çakmak, F. (2020). An account of EFL learners' self-efficacy and gender in the Flipped Classroom Model. Education and Information Technologies, 25(2), 4041-4055. https://doi.org/10.1007/s10639-020-10167-7.

[16] Namaziandost, E., Abedi, P., \& Nasri, M. (2019). The role of gender in the accuracy and fluency of Iranian upper-intermediate EFL learners' 12 oral productions. Journal of Applied Linguistics and Language Research, 6(3), 110-123

[17] Namaziandost, E., Sabzevari, A., \& Hashemifardnia, A. (2018). The effect of cultural materials on listening comprehension among Iranian upper-intermediate EFL learners: In reference to gender. Cogent Education,5(1), 1-27. https://doi.org/10.1080/2331186X.2018.1560601.

[18] Nittrouer, S., Mcgowan, R. S., Milenkovic, P. H., \& Beehler, D. (1990). Acoustic measure-ments of men's and women's voices: A study of context effects and covariation acoustic measurement. Journal of Speech and Hearing Research, 33, 761- 775.

[19] Pepiot, E. (2015). Voice, speech and gender: male-female acoustic differences and cross-language variation in English and French speakers. URL: http://corela.revues.org/3783.

[20] Rauber, A. S. (2006). Perception and production of English vowels by Brazilian EFL speakers. Unpublished doctoral dissertation Florianópolis: Universidade Federal de Santa Catarina.

[21] Shekaramiz, M. (2014). An acoustic study of vowel production in Persian aphasic speech. Language Science, 1(1), 131 - 145.

[22] Simpson, A. P., \& Ericsdotter, C. (2003). Sex-specific differences in F0 and vowel space. $16^{\text {th }}$ International Congress of the Phonetic Sciences (ICPhS XVI), Saarbrucken, Germany 933-936.

[23] Stevens, K. N. (2000). Acoustic phonetics. Cambridge: MIT Press.

[24] Xia, X. (2013). Gender differences in using language. Theory and Practice in Language Studies, 3, (8), 1485-1489. 